\title{
Nada que decir, sólo mostrar. Género y colonialismo en el fotomontaje de Hannah Höch
}

\author{
Irene Valle Corpas y Elisa Cabrera García \\ Universidad de Granada \\ irenevalle1991@gmail.com; elisacg@correo.ugr.es
}

RESUMEN: En la Alemania de entreguerras afectada por una profunda crisis económica y social, un grupo de artistas dadaístas desarrollaron el fotomontaje como única arma política con la que unir arte y vida en un mundo saturado de imágenes. El presente artículo analiza los collages fotográficos de uno de sus miembros, Hannah Höch, para conocer cómo, además de dar buena cuenta de los problemas que golpeaban a su país, pusieron de relieve las implicaciones políticas que albergaba la construcción de un imaginario del Otro (en su doble posición de género y raza). En este contexto, consideramos que las obras de Höch dan respuesta a un panorama político marcado por la inserción de la mujer en el mercado laboral y el imperialismo colonial, adelantando ideas de artistas de los años 70 informadas ya por la filosofía de la deconstrucción y la teoría queer.

PALABRAS CLAVE: Hannah Höch; Dadaísmo; Fotomontaje; Medios de masas; Nueva mujer; Colonialismo.

\section{Nothing to Say, Only to Show. Gender and Colonialism in Hannah Höch's Photomontage}

ABSTRACT: In interwar Germany, affected by deep social and economic crises, a group of Dadaist artists developed photomontage as the only political weapon to unite art and life in a world saturated with images. This article analyses the photographic collages of one of its members Hannah Höch; her work forms not only a visual record of the problems that beset her country, but also highlights the political implications harboured within the construction of an imagery of the Other (in its dual role of gender and race). In this context, we regard Höch's work as a response to a political landscape, marked by the integration of women into the labour market and colonial imperialism; and through doing so, Hoch's work anticipates the ideas of artists from the 1970's, already informed by the philosophy of deconstruction and the Queer Theory.

KEYWORDS: Hannah Höch; Dadaism; Photomontage; Mass Media; New Woman; Colonialism.

Recibido: 18 de febrero de 2017 / Aceptado: 10 de abril de 2017.

\author{
Hacer literatura con el revólver en el bolsillo fue mi anhelo durante algún \\ tiempo (Richard Huelsenbeck) \\ Me gusta tener las manos libres (Bertolt Brecht, Diálogo de refugiados)
}

El 9 de noviembre de 1918, pocos días después de que Alemania pidiese el armisticio a las potencias de la Triple Entente, el káiser Guillermo II se vio obligado a abdicar y nombrar a Friedrich Ebert, miembro del partido socialista (SPD), primer presidente de la recién nacida República de Weimar. Lo primero que hizo el nuevo gobierno fue reprimir brutalmente el levantamiento espartaquista que vio en el descontento de obreros y soldados fruto de la guerra y la miseria el caldo de cultivo perfecto para llevar a cabo una verdadera revolución en Alemania. Como es sabido las esperanzas fueron vanas, el movimiento fue aplastado y sus principales líderes silenciados o asesinados. A juicio de Hannah Arendt «con el asesinato de

Cómo citar este artículo: VALLE CORPAS, Irene y CABRERA GARCÍA, Elisa, «Nada que decir, sólo mostrar. Género y colonialismo en el fotomontaje de Hannah Höch», Boletín de Arte-UMA, n. ${ }^{\circ}$ 38, Departamento de Historia del Arte, Universidad de Málaga, 2017, pp. 179-188, ISSN: 0211-8483, DOI: http://dx.doi.org/10.24310/BoLArte.2017.v0i38.3289 
Rosa Luxemburgo y Liebknecht, la división de la izquierda europea en los partidos Socialista y Comunista se tornó irrevocable» (1990: 45), pues este crimen había sido perpetrado por las Freikorps, grupos paramilitares de extrema derecha con el apoyo del gobierno. «No podrá usted negarme que Alemania tenía un aspecto absolutamente democrático hasta el día en que empezó a tener un aire fascista». Así resumía Bertolt Brecht el período de Weimar y el nuevo cariz que adquirió la política alemana en pocos años ${ }^{1}$. Pero no menos profunda que la división política era la fractura social como consecuencia de una situación económica particularmente tumultuosa alimentada por la hiperinflación y la violenta desigualdad (Piketty, 2013: 514-515).

En mitad de este terremoto político y social, un grupo de intelectuales encabezados por Richard Huelsenbeck, que en 1918 acababa de llegar de Zurich con el dadaísmo en la maleta, fundan en Berlín el Club Dadá y una serie de revistas (Die Neue Jugend o Die Freie Strasse) con las que difundir una toma de posición ante el arte abiertamente crítica. Consideraban que su práctica era la única que había tomado el pulso al momento presente: el arte es la vida y la vida es política. En un pequeño texto titulado Dadá fue fundado en primavera Huelsenbeck lo expone así:

El arte supremo será aquel que en sus contenidos presente los millares de problemas de su tiempo, que denote que se ha dejado lanzar por las explosiones de las últimas semanas, que siempre vuelva a recuperar sus articulaciones empujado por el impulso del día anterior. [...] ¿Los expresionistas han cumplido nuestras expectativas de un arte que nos marque con hierro candente la esencia de la vida en nuestra carne? ¡No! ¡No! ¡No! (Huelsenbeck, 2000: 56-57).

Esta querencia de contemporaneidad implicaba una reflexión sobre la ciudad moderna, la reproductibilidad mecánica de la imagen y el espectacular desarrollo de los medios de masas. «Agarrarse al espíritu de la época» significaba mostrar la verdadera realidad del hombre moderno, que no era otro que aquel joven soldado alemán que a su regreso de la guerra no tenía más opción que ocupar un puesto de trabajo en una fábrica por un sueldo irrisorio y bajo duras condiciones laborales. Los nuevos obreros, trasladados de las filas del ejército a la cadena de producción fordista, fueron rápidamente asociados con la imagen del robot y el autómata descontrolado. Producidas ellas mismas en serie y cada vez más radicalizadas políticamente, las masas (urbanas) de trabajadores se convirtieron en el receptáculo de todo tipo de proyecciones, miedos y angustias de la burguesía (Wollen, 2006: 49). Los dadaístas no dudaron en poner todo el aparato mediático producido por el propio capital al servicio de un arte irónico y crítico que incidiese en esos temores subrayando la responsabilidad de la burguesía en la guerra y la subsiguiente crisis. Pero llegados a este punto, una pregunta parece obligada: ¿qué ocurre con la mujer? ¿Acaso no habían sufrido ellas también un cambio radical en sus formas de vida y en los arquetipos asociados a su género con motivo de la contienda? ¿No tenían ellas también «la esencia de la nueva vida marcada con hierro candente en su carne?».

En 1916 el número de mujeres que trabajaba en las fábricas alemanas había ascendido a 4,3 millones frente a los 4,5 millones de hombres. Obligadas a mantener un país entero con su trabajo en la retaguardia, a la vuelta de la guerra reclamaron representar un papel más activo en la recién creada República. Efectivamente con la caída del Káiser su situación cambió significativamente. Durante el periodo de Weimar se aprobaron derechos sociales para ellas y se intensificó el proceso de inserción de la mujer en el mercado laboral y su participación en las esferas públicas. A esto hemos de añadir el hecho de que en el contexto de la Europa de entreguerras, afectada por un descenso de la población masculina, se promulgaron leyes para el control de la natalidad y de forma general se extendieron los debates sobre la importancia de la sexualidad en la vida social -no olvidemos que son los años en los que se dan a conocer las obras de Freud (Sawelson-Gorse, 1998: 13). Desde numerosas publicaciones de índole femenina se lanzaban imágenes de una nueva mujer fuerte y trabajadora. Es cierto que aumentó sustancialmente la ocupación femenina, pero la realidad fue que la mayoría de estos trabajos significaban mano de obra barata y regímenes laborales abusivos que se justificaban como la forma de devolver a Alemania su potencia industrial. La visión que las revistas presentaban de esta Neue Frau era la realidad de una escasísima minoría de mujeres burguesas «emancipadas» mientras que el resto, la gran mayoría, se repartían el trabajo entre la industria de armamento, las fábricas y las minas por sueldos muy bajos y en condiciones infames. De este modo, la imagen que se construyó de la mujer 
osciló entre la moderna flapper, supuestamente desinhibida en lo sexual, vestida à la Chanel, que usaba electrodomésticos recién salidos al mercado y tomaba partido en la política; y aquella otra representación de una masa de obreras más maquinal que sus homólogos hombres, y decididamente mucho más amenazadora. Höch no solo supo reconocer esta fuerte brecha social sino que además, sus obras dan cuenta de ese proceso de androginización que está detrás de la imagen de la Neue Frau. Como explica Maud Lavin, durante este periodo temprano, la única herramienta de emancipación femenina venía determinada por un acercamiento a posturas que cupiesen dentro del marco de lo que podía ser considerada la masculinidad (1990: 75). Estas consideraciones sobre la inclinación de las mujeres a las esferas de lo masculino enfatizan más, si cabe, el carácter plenamente irónico presente en los fotomontajes andróginos de Höch y su capacidad para hacer saltar todas las contradicciones inherentes a una distribución de géneros plenamente machista. Igualmente y como ha indicado Andreas Huyssen, en la época de entreguerras, con el incipiente acceso femenino al ámbito laboral y político, «el temor a las masas es también el temor a la mujer, a la naturaleza fuera de control, temor a lo inconsciente, a la sexualidad, a la pérdida de la identidad y del Yo estable en la masa» (2006: 103) ${ }^{2}$. Hannah Höch era consciente de este hecho y sus collages funcionan como mecanismos que ponen en marcha ese imaginario, al tiempo que combinaba esta preocupación con una crítica política hoy ya incuestionable. A pesar de ello nunca gozó del reconocimiento de sus compañeros, que no entendían el valor político de unas obras que aludían a cuestiones a su juicio psicologizantes, subjetivas y poco inteligibles. Se hace evidente que tales censuras no sólo faltaban a la verdad -pues en la producción de Höch encontramos piezas abiertamente políticas como A la cabeza del estado (1930), Altas Finanzas (1923) o su conocidísimo Corte con un cuchillo de cocina en la barriga cervecera de la República de Weimar (191920)- sino que, sobre todo demostraban una limitación en la comprensión de las estrategias políticas que la obra de esta artista ponía en juego. En su monografía sobre Höch, Maud Lavin es tajante al respecto:

Although it is true that Höch's work does not covey the explicit and often prescriptive political messages of Heartfield's photomontages, it is important to recognize that other politi- cal strategies were available. As we have seen, Höch developed a sophisticated critical language of social commentary concerning the typology and conditions of the modern woman (Lavin, 1993: 159).

Pero, volvamos a las palabras de Huyssen. Pues, a pesar de que es evidente que Höch quiso llevar a cabo un comentario sobre la moda y la publicidad como generadores de sueños rotos o incluso de perversiones -en un gesto muy en consonancia con los escritos de Walter Benjamin acerca de la moda como imagen del progreso que va dejando tras de sí una ruina, un cadáver sobre el cuerpo de la mujer convertido en fetiche-, la maniobra política de la artista alemana es algo más compleja. Su objetivo parece ser precisamente un intento por violentar esa «identidad del yo estable», e incluso del propio «yo de Alemania», al introducir un "otro» que compendiase a todos los otros posibles. Nos referimos a la habilidad con la que Höch hizo confluir los significantes «mujer», «negro» y «primitivo» en un cúmulo de imágenes que incidiesen en las contradicciones que albergaban los prototipos del hombre blanco dominador y su correlato en la Neue Frau. Con ello trataba de socavar los pilares de una sociedad tan patriarcal como la alemana que aunque lanzaba constantes mensajes de «modernidad» estaba sustentada en la familia, la represión sexual y el relato de un pasado colonial glorioso. Pero a partir de 1918 estos esos relatos comenzarían a agrietarse y es en esas fisuras, en esos cortes donde incide la obra de Höch.

En la acuciante tarea de incorporar a la praxis artística los problemas del presente anulando todo límite entre arte y vida, sin duda el fotomontaje se antojaba mucho más efectivo que el óleo o cualquier otro medio tradicional. La actitud del pintor de izquierdas provisto de una colección de «temas revolucionarios», en poco o nada había contribuido a liquidar los mecanismos con los que la burguesía se las ingeniaba para enclaustrar el arte en una esfera autónoma. A juicio de Benjamin, un firme defensor de esta vanguardia, Dadá Berlín se había percatado de la necesidad de sortear la posición del «rutinero», ese «lugar imposible» que entorpecía la auténtica tarea del artista revolucionario: mostrar los procesos de producción que habían traído consigo una escisión insalvable entre significante y significado, un vaciamiento de sentido que afectaba no sólo a los objetos, sino también al trabajo y al propio cuerpo humano, y en especial al femenino ${ }^{3}$. Para 


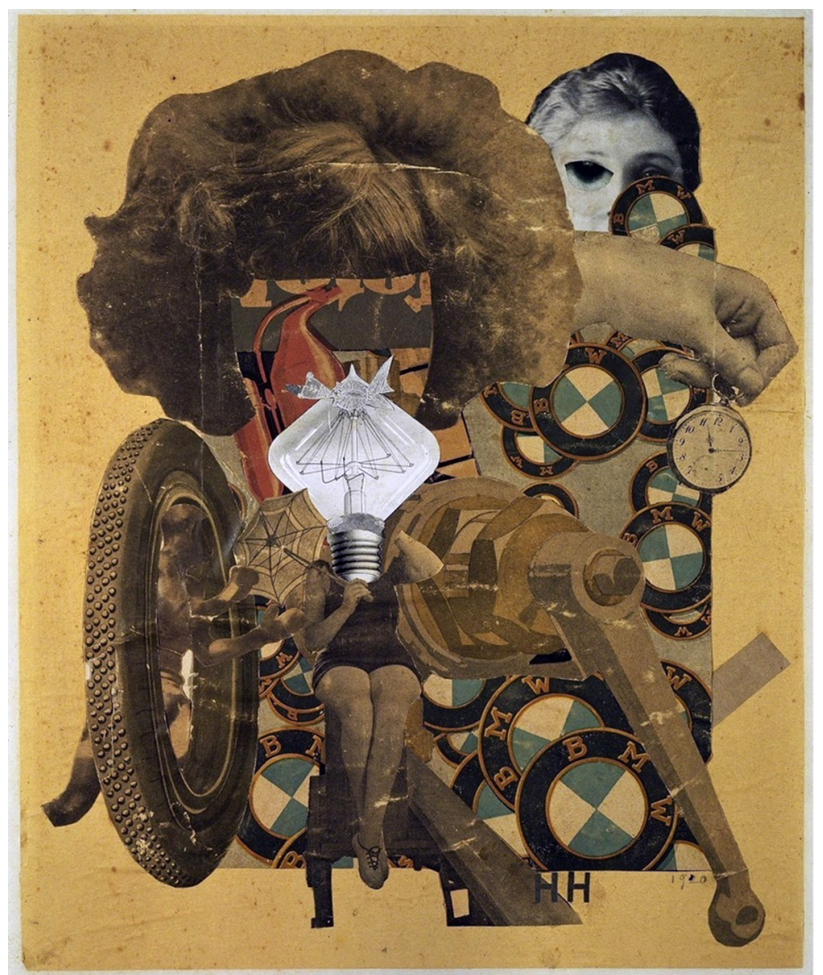

1. Hannah Höch, Das schöne Mädche (La chica guapa), 1920

hablar sobre ese mundo contingente de los medios de comunicación y la mercancía, saturado de imágenes que amenazaban con borrar las barreras entre alta y baja cultura y poblado por sujetos fragmentados, era necesario convertirse en bricoleur, crear objetos o productos (Erzeugnis) manipulando los desperdicios y desechos más variados de la realidad. En un primer momento estos fragmentos quedan desposeídos de su significado en una operación simétrica a la que había sufrido el objeto al transformarse en mercancía (Buchloh, 2004: 91), para que seguidamente y a partir de su yuxtaposición dialéctica emerja un nuevo significado o alegoría en la acepción más benjaminiana del término. En el fotomontaje el sentido penetra a través de los elementos más nimios de la cotidianeidad, y además, lo hace en función de las relaciones que se desencadenan entre las partes. Queda así certificado que, como el montaje mismo, toda realidad está construida no a partir de substancias sino como un conjunto de relaciones mutables. En palabras del propio Huelsenbeck, «dadá es la falta de relación con todas las cosas y tiene por consi- guiente la capacidad de establecer relaciones con todas las cosas» (cit. en Marchán Fiz, 2012: 39). Rosalind Krauss ha advertido que en el fotomontaje dadá hay muchos espacios en blanco, vacíos y huecos que separan de un modo claro cada uno de los elementos del collage. La imagen fotográfica "se ve despojada de la sensación de presencia» haciendo que el espectador intuya fácilmente que al mirar el mundo nuestros ojos están contaminados por la interpretación y la significación, es decir, que toda realidad está «dilatada por los vacíos y los blancos que constituyen las condiciones formales preliminares para la existencia del signo» (Krauss, 2002: 117). Pero, lo que es aún más importante, es que mediante la elección de materiales heterogéneos, cada cual captado en su toma original desde un ángulo diverso, el fotomontaje certifica que la visión, al igual que la realidad sobre la que se posa el ojo, depende de relaciones y puntos de vista posiblesVéase (véase Chevrier, 2011:185). Marchán Fiz va aún más lejos e indica que el carácter relacional del fotomontaje lo escora hacia una "estética del acontecimiento, si es que no traspasando abiertamente los umbrales de una estética de lo performativo» (2012: 39).

Este trabajo de despojar la presencia y deshacer la imagen en favor de un arte que se concentra en las junturas y los márgenes, es llevado a su máxima expresión en los fotomontajes de Höch. En sus obras las distintas partes del cuerpo adquieren el valor de meros significantes que flotan como fragmentos combinándose hasta transfigurarse en seres monstruosos en las antípodas de aquellos personajes fuertes y bellos de los que estaban tomados los recortes -con frecuencia extraídos de revistas como Die Dame o Die Praktische Berlinerin con las que Höch había colaborado-. Valgan como ejemplo El padre (1920) que muestra a un hombre con vestido y piernas de mujer acunando a un bebé y rodeado de figuras femeninas muy activas (una bailarina o una nadadora); o La chica guapa (1920) [1] donde unos pocos elementos que se repiten (el logo de la BMW, una rueda de coche, una bombilla, unas piernas y una careta de mujer), crean la imagen de una mujer sin rostro ni rasgos, maquinal y producida en serie como objeto de consumo. Pero, lo que es aún más revelador es que en series como Desde el museo etnográfico (Aus einem Ethnographischen Museum 1924-1933) esos «seres monstruosos" o híbridos en todo caso, están compuestos de pedazos de cuerpos femeninos combinados con imágenes de culturas no-Europeas de Áfri- 
ca, el este y sureste asiático y las islas del Pacífico, dando alas a una lectura interseccional poscolonial y de género en la obra de la artista ${ }^{4}$.

No podemos olvidar que en 1918 Alemania perdió su imperio colonial. El gobierno de la República, junto con el grupo colonialista más importante del país, la Deutsche kolonialverein (Sociedad Colonial Alemana), respondió a esta pérdida desarrollando una campaña de propaganda destinada a fomentar la readquisición de los territorios coloniales bajo pretextos como la recuperación del «espacio vital» o la necesidad de civilizar a otras razas «subdesarrolladas» (Makela, 1996: 72). Desde la década de 1880, momento en el que Alemania comienza su andadura colonial en el país germano, se conformaron algunas de las colecciones de objetos etnográficos más grandes del mundo, incluyendo el Ethnographisches Museum de Dresde o el Museum für Völkerkunde situado en Berlín (véase Makela, 1996). Höch conocía estos objetos de primera mano o a través de revistas como Der Querschnitt, editada por el coleccionista y marchante de «arte tribal» Alfred Flechtheim, que gozaban de una gran popularidad en la Alemania de entreguerras. En muchos casos eran los propios coleccionistas quienes montaban exposiciones de sus botines traídos de los Mares del Sur y otros rincones lejanos que solían ir acompañadas de catálogos y artículos con abundante material fotográfico sobre la vida «tribal» de esas gentes ${ }^{5}$. Höch también pudo familiarizarse con estas imágenes a través de la obra de los expresionistas de Die Brucke igualmente próximos a la estética tribal. Sin embargo, como ella misma manifestó, su acercamiento pretendió ser «mucho menos serio» que el de sus colegas expresionistas, más irónico y distanciado en el sentido brechtiano del término y quizá por ello más perturbador. Ya en 1924 hizo referencia inequívocamente al discurso de la época sobre la raza en Mischling (Mestizo) [2], un fotomontaje que une la boca de una mujer blanca con la cara de una mujer negra, o en Liebe im bush (Amor en el arbusto, 1925) [3], donde podemos ver a un hombre negro abrazando a una mujer blanca. Tal manifestación de «amor» se antoja totalmente radical en un momento en el que cualquier vínculo entre hombres negros y mujeres blancas era considerado violación por la gran mayoría de la sociedad alemana.

En su ya clásico artículo The Primitive Unconscious (1985) Hal Foster arrojó luz sobre la conceptualización de lo primitivo que la cultura europea detentó hasta hace es-

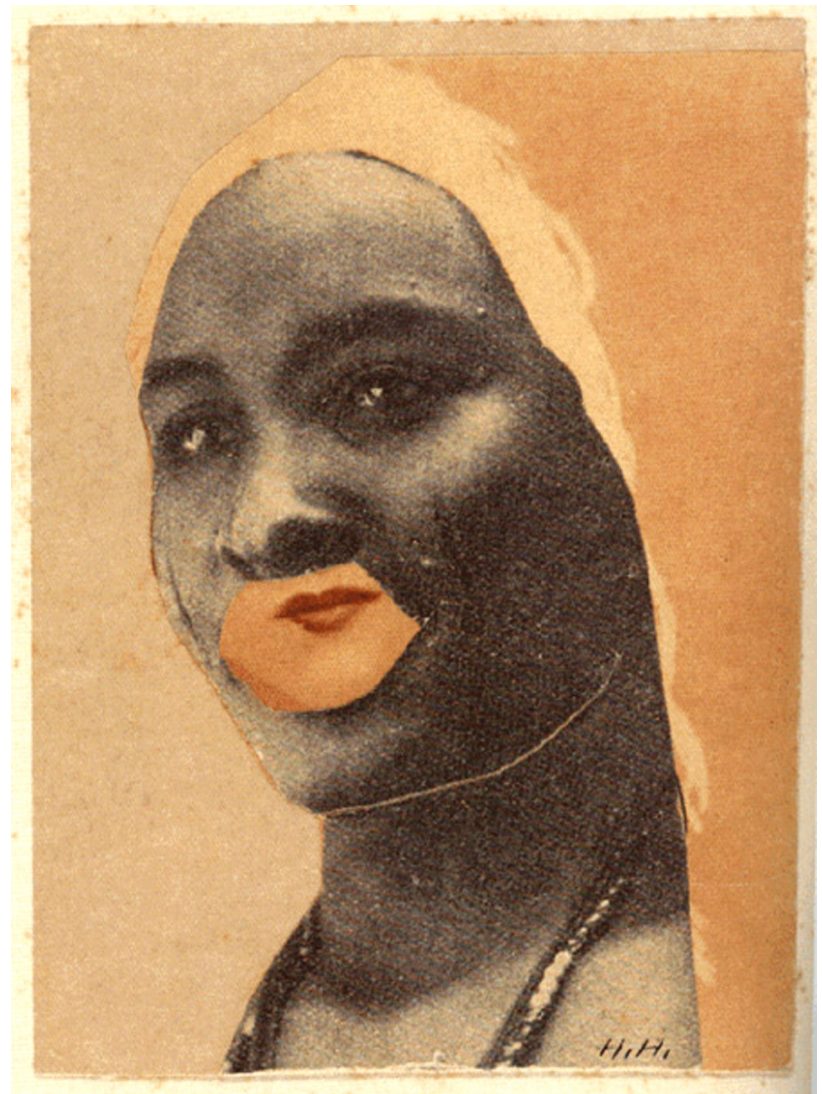

2. Hannah Höch, Mischling (Mestizo), 1924

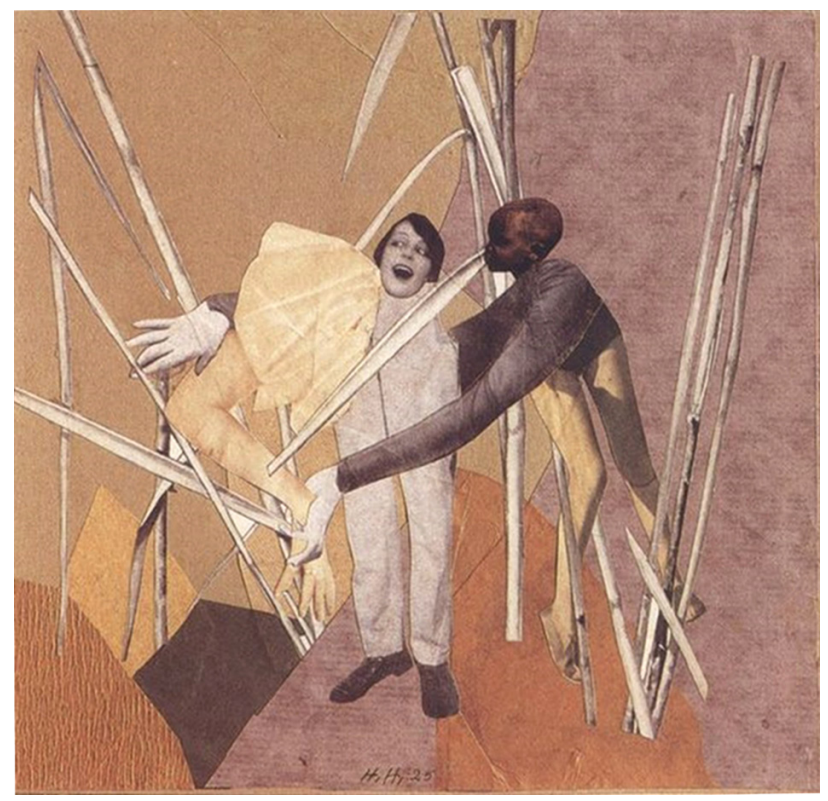

3. Hannah Höch, Liebe im bush (Amor en el arbusto), 1925 


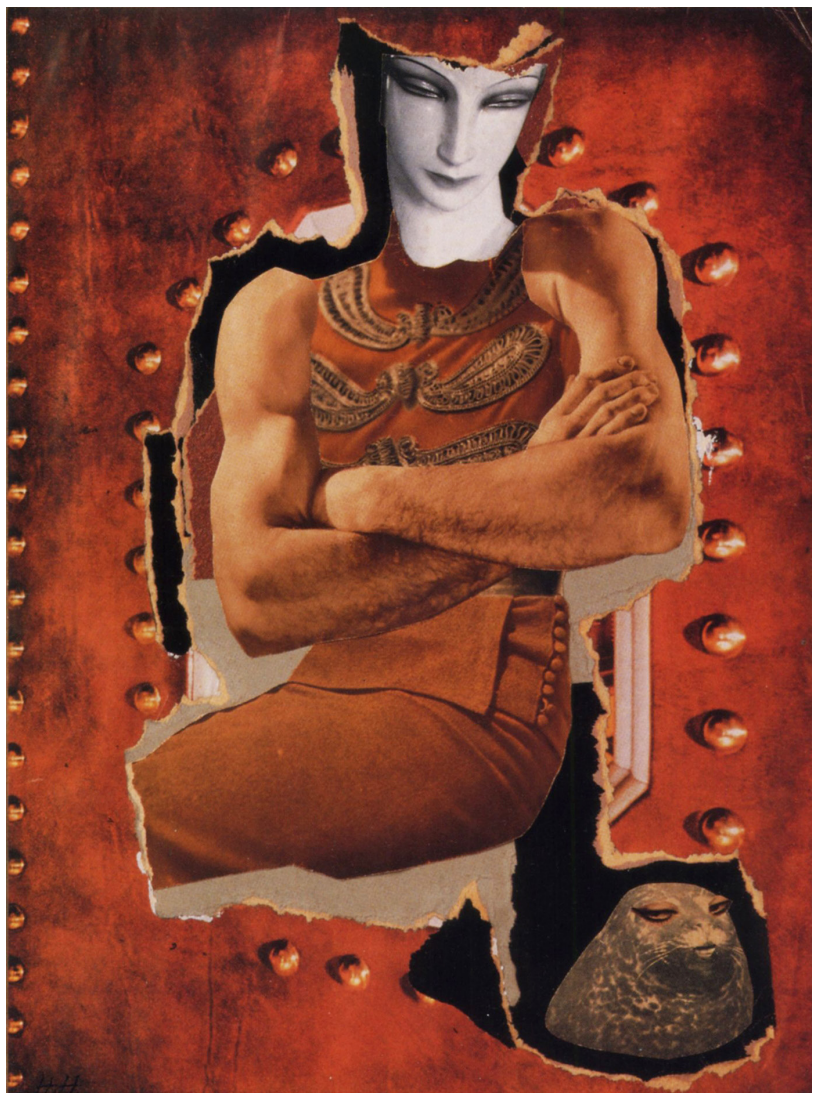

4. Hannah Höch, Tamer (Domador), 1930

casas décadas: el primitivismo como discurso fetichista de dominación en tanto que trata de reconocer y negar al mismo tiempo la diferencia del otro y la amenaza asociada a la pérdida de una determinada concepción del mundo que el otro pueda producir. En opinión de Foster el primitivismo es un mecanismo compensatorio ideado precisamente para lidiar con esa amenaza. Se trata de una suerte de dispositivo inmunológico que frenaría el posible contagio de lo externo convirtiéndolo en objeto que además pueda ser consumible. En contraste con esta posición cómoda del primitivista, Höch socava la percepción inicial que el espectador se hace del otro como un objeto real y completo (su presencia), al llamar la atención sobre su naturaleza fragmentaria y construida. Apropiándonos de las palabras de Deleuze y Guattari podríamos decir que «hay, en un momento dado, un mundo tranquilo y sosegado. Aparece de repente un rostro asustado que contempla algo fuera del ámbito delimitado.
El Otro no se presenta aquí como sujeto ni como objeto, sitio, cosa sensiblemente distinta, como un mundo posible, como la posibilidad de un mundo aterrador» (Deleuze, Guattari, 1991: 22). El temor a aquello que estaba en el margen y su elaboración como objeto llevó a Höch a conectar las imágenes de mujeres fetichizadas con la de los objetos tribales, actuando como una auténtica bricoleuse que deja al descubierto los recursos del discurso primitivista. Estela Ocampo en un trabajo reciente, ha trazado esta línea de unión histórica entre primitivismo y feminidad que permitió a diversas artistas del siglo XX «vehicular su cuestionamiento de los roles establecidos en un discurso de alto contenido político» $(2015,316)$. Según la autora, en el caso de Höch el resultado dinamita la representación de la mujer como «objeto bello» y actúa como crítica a la fetichización.

Dicho esto, hemos de tener muy presente la advertencia de la historiadora Maud Lavin, para quien sería ridículo adscribirle a la alemana una consciencia plenamente poscolonial que reconociera ya en los años 20 el racismo subyacente a tales descripciones de la «negritud». Lejos de esta postura a todas luces ahistórica, consideramos que si Höch supo apreciar el gesto político escondido en el trabajo con los cuerpos híbridos es ante todo debido a su empeño por llevar la lógica alegórica del collage, el trabajo sobre las fisuras de la imagen, a sus últimas consecuencias:

\footnotetext{
Me gustaría borrar los límites fijados que a los humanos, seguros de nosotros mismos, nos gusta dibujar alrededor de cualquier cosa que podamos conseguir. Deseo seguir formulando la advertencia de que, aparte de tu concepción y tu opinión y las mías, existen millones y millones de otros modos de ver legítimos.
}

Pero a pesar de la llamada al rigor histórico de Lavin, no debe sorprendernos que fuese en la década de los setenta, segundo ola del feminismo, cuando una serie de artistas plásticas elaborasen obras que mutatis mutandi se trataban de fotomontajes «a lo Höch», con los que pretendían nuevamente poner de relieve la naturaleza construida del cuerpo femenino como producto de unos intereses políticos muy determinados y en un mundo ya plenamente dominado por la imagen. Tanto es así que algunos collages de la alemana parecen avanzar los mejores trabajos de Barbara Kruger, Cindy Sherman y especialmente Martha Rosler [4] ${ }^{6}$. De esta 
última podríamos citar piezas absolutamente tributarias de la investigación de la alemana como Small Wonder o Hot Meat, ambas de la serie Body Beautiful, or Beauty Knows No Pain fechada entre1966 y 1972 [5]. Y su vídeo Martha Rosler reads vogue $^{7}$ [6] realizado en 1982 nos presenta a la artista comentando las consignas ideológicas que emite la publicidad de esta revista de moda normalmente vertidas sobre el cuerpo femenino, mientras Rosler pasa el dedo por las imágenes señalando las partes que parece hubiera recortado para uno de sus montajes. $Y$ en este gesto casi podemos ver el mismo proceder que debió de seguir Höch ante su mesa de maquetaciones abarrotada de revistas que salvando las distancias eran las mismas Vogue que Rosler despedazaba en sus obras. Aunque, claro está, en el entorno de los años setenta marcado por el nacimiento de la política de identidades y la importancia dada a lo micropolítico, el trabajo de Rosler y compañía se elabora desde el cuerpo y con plena consciencia política de lo que ello implica.

En el ámbito de la historiografía, habría que esperar hasta la década de los noventa para volver a encontrar su nombre como miembro de pleno derecho en cualquier listado de creadores notables de las vanguardias históricas. La historiografía de la Alemania natal de Höch empieza a recuperar su figura de forma intensiva coincidiendo con la caída del muro, que permitió el flujo de documentación entre las instituciones del Berlín del este y el del oeste, y tomando como referencia el centenario del nacimiento de la artista en 1989. Anteriormente habían visto la luz ciertas publicaciones relacionadas con exposiciones temporales de museos y galerías del país pero nada comparable a la ingente bibliografía que podía encontrarse sobre sus colegas. Esta falta queda cubierta en los últimos compases del siglo. En 1990 la Berlinische Galerie le dedica una muestra monográfica y a lo largo de esta década su figura cobra importancia en la academia norteamericana debido en gran parte a la implantación en las universidades de este país de los Estudios Culturales centrados en rescatar y estudiar parcelas olvidadas en el relato rígido y occidental de la Modernidad, desde el arte producido por cualquier tipo de sujeto periférico a las diversas manifestaciones de la cultura popular.

Es Maud Lavin quien marca la agenda en torno a Höch con su monografía Cut with the Kitchen Knife (1993) que será seguida en las tres grandes exposiciones sobre su obra organizadas hasta la fecha: en el MoMA en el 97, aquella ela-

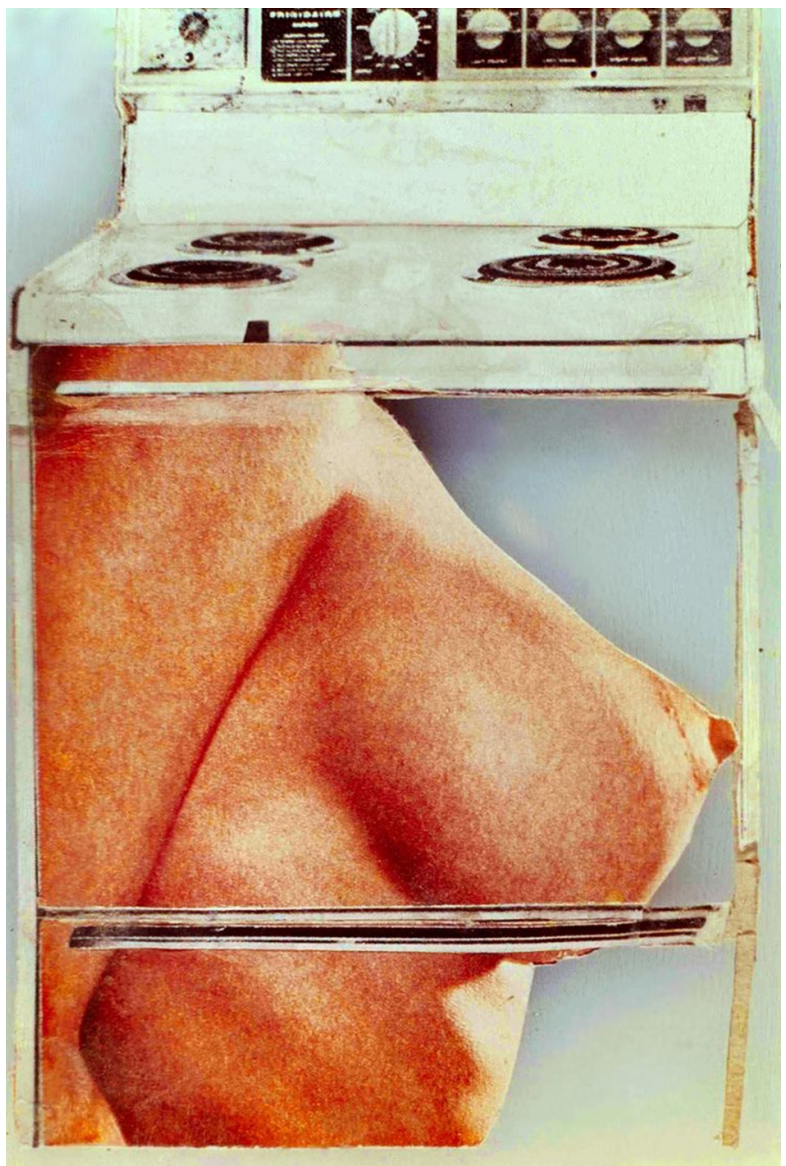

5. Martha Rosler, Hot Meat in Body Beautiful, or Beauty Knows no Pain (Carne caliente de la serie Cuerpo belleza o la belleza no conoce el dolor), 1969

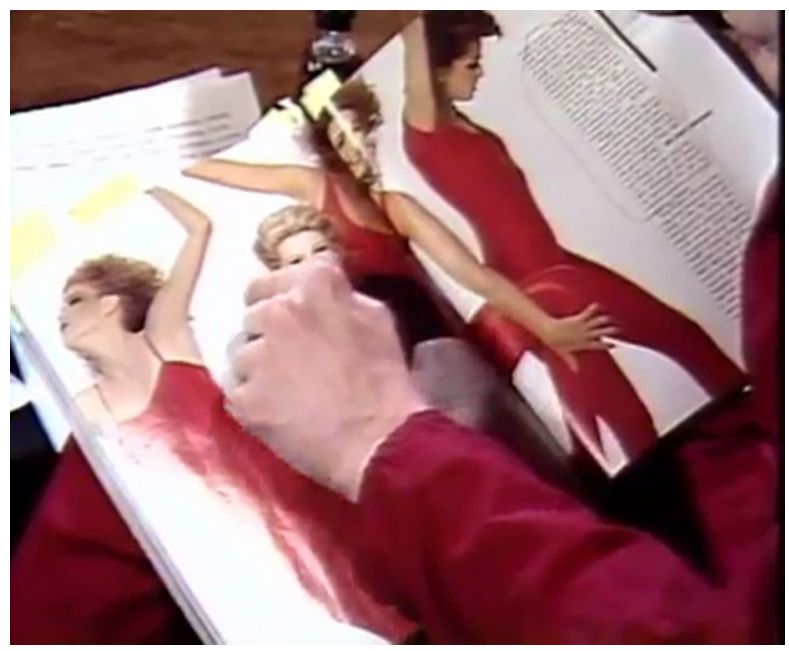

6. Marta Rosler, fotograma del vídeo Martha Rosler reads vogue (Martha Rosler lee el vogue), 1982 
borada en el Museo Nacional Centro de Arte Reina Sofía en 2014 o la ideada por la Whitechapel Gallery de Londres en el mismo año. Por último, tampoco es gratuito que sea 1990 el año en que se publicasen dos ensayos indispensables para llevar a cabo esta revisión de las aportaciones de Höch y otras artistas de vanguardia. Nos referimos a Gender Trouble. Feminism and the Subversion of Identity, de la filósofa Judith Butler y Yearning. Race, Gender and Cultural de la escritora feminista negra Bell Hooks. Buen ejemplo de esta tendencia que vuelve sobre obras de autoras condenadas al olvido fue la exposición organizada en 1997 Rrose is a Rrose is a Rrose. Gender Performance in Photography que contaba con hasta 5 fotomontajes de Höch. Según el catálogo en la obra de la alemana existe una crítica implícita a la rigidez normativa de la publicidad presente en los medios de la Alemania de Weimar. Asimismo alude al hecho de que los títulos de los montajes de este periodo se referían frecuentemente a artistas de variedades, performers y miembros marginales de la sociedad berlinesa; una mezcolanza de artistas circenses, actores y personajes del mundo del espectáculo, lugar al que se veían relegados, condenados al ostracismo debido a su falta de conformidad con la normatividad establecida. A juicio de las autoras, sus sujetos híbridos estarían personificando lo que la teoría queer ha denominado category crossers, personas que representan identidades ambiguas que exponen «lo tenue de la realidad de género» (Butler, 29). Tanto es así que el catálogo llegará a afirmar que es esta juxtaposición de partes distintas la que causa un gender trouble en los fotomontajes de Höch. Y si tomamos algunos pasajes de la conocida obra de Butler y los leemos con las imágenes de fotomontajes arriba citados en mente, podemos intuir que, en buena medida, esta lectura que se inclina hacia el «travestismo» en la obra de Höch, puede a encajar:

Cuando tales categorías se ponen en tela de juicio, también se pone en duda la realidad del género: la frontera que separa lo real de lo irreal se desdibuja. Y es en ese momento cuando nos damos cuenta de que lo que consideramos «real», lo que invocamos como el conocimiento naturalizado del género, es, de hecho, una realidad que puede cambiar y que es posible replantear, llámese subversiva o llámese de otra forma. Aunque esta idea no constituye de por sí una revolución política, no es posible ninguna revolución política sin que se produzca un cambio radical en nuestra propia concepción de lo posible y lo real (Butler, 28) [el subrayado es nuestro].

Sea como fuere, y aunque en cierto sentido estos catálogos nos hablan más del intento, a todas luces enriquecedor, de revisar la obra de Höch desde la teoría queer y los estudios poscoloniales que de sus propias inquietudes, de lo que no cabe duda ya es de que su labor, labrada siempre en las fronteras y los espacios en blanco, implica una estrategia política de primer orden al emplear aquello que los discursos racista y masculinista más temían: la hibridez ${ }^{8}$. Aunque aquella "chica buena» ${ }^{9}$ tuvo que esperar demasiados años para que se reconociese su trabajo, afortunadamente hoy ya nadie duda de que Hannah Höch también quiso hacer arte con el revólver en el bolsillo.

\section{Notas}

* Este artículo ha sido realizado gracias al apoyo del proyecto «El género, la mujer y lo femenino en las referencias filosóficas y literarias de los siglos XVIII y XIX estudiadas por Walter Benjamin».

1 Efectivamente, el mejor relato de la miseria política del gobierno de la República nos lo brinda concentrado en solo dos páginas de su imprescindible Diálogo de Refugiados (Brecht, 1995:109-110).

2 Raoul Hausmann parecía compartir este interés destructor del Yo cuando afirmaba, «Dadá es la desintoxicación práctica del Yo, un estado euro-occidental, antioriental y no mágico» (en Chevrier, 2011: 188). Sin embargo, sería Höch la única miembro del grupo que se hiciese cargo de las implicaciones de género y sexuales implícitas en ese Yo.

3 Peter Wollen señala que el «fordismo introdujo -para el trabajador- un régimen industrial de puros significantes» al abstraer la tarea del obrero y reducirla a un único gesto absolutamente racionalizado y carente de significado (Wollen, 2004: 61). La distinción entre el rutinero y el productor ha sido tomada de Benjamin (2015: passim). En lo que se refiere a la repercusión sobre el objeto de la llegada de los nuevos procesos de producción y reproducción mecánicos, es bien sabido que fue el propio Benjamin quien más insistió en que la división entre valor de uso y valor de cambio provocaría la conversión de todo objeto en mercancía, incluida la obra de arte. En cuanto al desmembramiento del cuerpo humano y su conversión en imágenes separadas ya de cualquier referente y expuestas como un objeto más o una pieza más en el engranaje de una máquina, responde a las mismas pautas, la mecanización y racionalización moderna. En este punto, nos remitimos a los estudios de Hal Foster sobre las obsesiones de los surrealistas con los autómatas, los maniquís, las muñecas y otras figuras (in)humanas que en cierto sentido eran compartidas por los dadaístas alemanes aunque como bien señala el estudioso norteamericano, la respuesta a esta problemática por parte de cada vanguardia fue distinta (Foster, 2008: 211-251). 
4 Esta es expresamente la línea de trabajo trazada por Kristin Makholm en su tesis doctoral (Film Portraiture and Primitivism in the Photomontages of Hannah Höch, Universidad de Minnesota, 1999), parte de cuyo contenido sería posteriormente trasladado al catálogo de la exposición Hannah Höch celebrada en el MNCARS en 2004. Igualmente el estudio preliminar de Maria Makela para el catálogo de la muestra The Photomontages of Hannah Höch del Walker Art Center de Minneapolis, publicado en 1996, se reafirma en la necesidad de tomar en consideración la cuestión del género y la raza como elementos imbricados en la obra de Höch.

5 Makela apunta que por lo menos siete de las composiciones de la serie Desde el museo etnográfico están confeccionadas con el número de enero de 1925 de la revista de Flechtheim.

6 Hemos de puntualizar que no todas las mujeres artistas de los años sesenta siguieron esta estrategia de denuncia de la presencia intensa de imágenes de cuerpos femeninos, en ocasiones vinculados con lo primitivo, como una señal de cosificación. En cambio, algunas parecieron encontrar en lo que se había venido considerando "arte primitivo»-lo que actualmente no puede dejar de parecernos un ejercicio de apropiacionismo cultural-, una vindicación del "cuerpo como trasmisor de significados» (Ocampo, 2015: 318) que les permitió articular una crítica al marco de inteligibilidad artística de la época. Tanto es así que según Ocampo, creadoras como Carolee Schneemann y Ana Mendieta utilizan asociaciones similares para reivindicar «el cuerpo femenino como Creación, Naturaleza, Tierra, o Maternidad [...] [y] despojándola de sus contenidos despectivos dentro de la cultura occidental, reivindicar, como en los pueblos primitivos, el cuerpo femenino como metáfora de la potencia creadora» $(2015,317)$. No podemos perder de vista que algo después del momento cumbre de las obras de Mendieta y Schneemann las filósofas feministas francesas como Irigaray o Cixous, seguidas de sus colegas italianas (Murano, etc.), están desarrollando sus textos sobre la diferencia que reclaman los rasgos distintivos de las mujeres como la maternidad, la lactancia, los cuidados, etcétera para dotar de un nuevo papel de trascendencia a los mismos.

7 Puede encontrarse en red aquí: https://www.youtube.com/watch?v=Z3toLPAvhM4.

8 Véase el capítulo «Lustmord. La violencia contra las mujeres en el arte de la Alemania de entreguerras» en Aliaga, 2007: 67-120.

9 Así es descrita por Hans Richter en su libro DADA-Kunst und Antikunst, publicado en 1964.

\section{Bibliografía}

ALIAGA, Juan Vicente (2007), Orden fálico. Androcentrismo y violencia de género en las prácticas artísticas del siglo XX, Akal, Madrid. ARENDT, Hannah (1990), Hombres en tiempos de oscuridad, Gedisa, Barcelona.

AA.W. (2004), Hannah Höch: catálogo de exposición, Museo Nacional Centro de Arte Reina Sofía, Madrid.

BENJAMIN, Walter (2015), El autor como productor, Casimiro, Madrid.

BUCHLOH, Benjamin (2004), Formalismo e Historicidad. Modelos y métodos en el arte del siglo XX, Akal, Madrid.

BRECHT, Bertolt (1995), Diálogo de refugiados, Alianza, Barcelona.

BUTLER, Judith (2001), El género en disputa. El feminismo y la subversión de la identidad, Paidós, Barcelona.

CHEVRIER, Jean-François (2011), Les relations du corps, L'Arachnéen, París.

DELEUZE, Gilles y GUATTARI, Felix, ¿Qué es la filosofía?, Anagrama, Barcelona, 1991.

FOSTER, Hal (1985), «The 'Primitive' Unconscious of Modern Art», October, vol. 34, pp. 45-70.

- (2008), Belleza Compulsiva, Adriana Hidalgo editorial, Buenos Aires.

HAUSMANN, Raoul (1992), Courrier Dada, Allia, París.

HOOKS, Bell (1992), «The oppositional Gaze. Black Female Spectators», en Black Looks. Race and Representations, South End Press, Boston. HUELSENBECK, Richard (2000), Avant Dadá. El club dadá de Berlín, Alikornio ediciones, Barcelona.

HUYSSEN, Andreas (2006), Después de la gran división. Modernismo, cultura de masas, posmodernismo, Adriana Hidalgo editora, Buenos Aires. KRAUSS, Rosalind (2002), Lo fotográfico: por una teoría de los desplazamientos, Gustavo Gill, Barcelona.

LAVIN, Maud (1993), Cut with a Kitchen Knife, Yale University Press, New Haven.

- (1990), «Androgyny, Spectatorship, and the Weimar Photomontages of Hannah Höch», New German Critique, n. ${ }^{\circ} 51$, pp. $62-86$.

MAKELA, Maria et al. (1996), The Photomontages of Hannah Höch, Minneapolis, Walker Art Center.

MARCHÁN FIZ, Simón (2012), Del arte objetual, al arte de concepto. (1960-1974), Akal, Madrid.

OCAMPO, Estela (2016), «Primitivismo y Feminismo en el arte contemporáneo», Arte, Individuo y Sociedad, vol. 28, n. ${ }^{\circ}$ 2, pp. $311-324$.

- (2016), «Contemporary Artist on Colonial Museums», Boletín de Arte, n. ${ }^{\circ}$ 37, pp. 35-48.

PIKETTY, Thomas (2013), Le capital au XXle siècle, Éditions du Seuil, París.

SAWELSON-GORSE, Naomi (ed.) (1998), Women in Dada: Essays on Sex, Gender, and Identity, MIT Press, Cambridge.

WOLLEN, Peter (2006), El asalto a la nevera: reflexiones sobre la cultura del siglo XX. Akal, Madrid. 
